\title{
Research on Prevention and Control of Risk Index of Groundwater Pollution System in Northeast China
}

\author{
Mingtan Zhu*, Bo Li \\ School of Ecological Environment, Chengdu University of Technology, Chengdu, China \\ Email address: \\ 1289405646@qq.com (Mingtan Zhu), 1063624529@qq.com (Bo Li) \\ ${ }^{*}$ Corresponding author
}

To cite this article:

Mingtan Zhu, Bo Li. Research on Prevention and Control of Risk Index of Groundwater Pollution System in Northeast China. International Journal of Environmental Protection and Policy. Vol. 9, No. 5, 2021, pp. 123-129. doi: 10.11648/j.ijepp.20210905.14

Received: September 24, 2021; Accepted: October 30, 2021; Published: November 5, 2021

\begin{abstract}
The background of this paper is that groundwater pollution risk assessment and zoning is an important basis for regional groundwater resources protection. The research progress and deficiency of Groundwater Hazard Risk Assessment at home and abroad are analyzed. Based on the data of 18 water quality indexes such as ammonia and nitrogen in 18 groundwater monitoring sites in Jinzhou area, the pollution factors and pollution sources were analyzed with the improved Mero comprehensive index. At present, due to the long-term exploitation of shallow groundwater in the west of Liaoning Province, the pollution degree of the groundwater is relatively large, and the cause of the pollution is unknown. The research methods are literature research and case analysis. On the basis of defining the risk of groundwater pollution, the index system of groundwater pollution risk assessment and the index system of groundwater pollution risk assessment are established. The results show that nitrate is the main factor of regional groundwater pollution, and the contribution of variance is $49.30 \%$. Domestic sewage is the main source of regional shallow groundwater pollution. At the same time, an improved Mero composite index was proposed to strengthen the control of domestic sewage and agricultural non-point source pollution in Jinzhou, and to strengthen groundwater recharge, the impact of transgression on groundwater quality in Jinzhou should also be the focus of follow-up studies.
\end{abstract}

Keywords: Méreau Composite Index, Groundwater Pollution Risk Assessment, Index System, Disaster Risk Theory

\section{Introduction}

Groundwater is an important part of the water resources that humans rely on for survival, a precious natural resource, and one of the most important factors affecting the ecological environment [1]. For the Northeast region, groundwater resources are not only a basic resource for regional development, but also a strategic resource and an important guarantee for urban development. According to surveys, 97\% of urban groundwater in my country is polluted to varying degrees, and $40 \%$ of the pollution aggravated due to slow groundwater flow, low changes, and low self-purification capabilities. Contaminated, it is difficult to recover effectively. Therefore, prevention of groundwater pollution and effective monitoring are particularly important. Groundwater pollution risk assessment and zoning are important means to protect regional groundwater resources. Through groundwater pollution risk assessment, we can understand the relationship between land use activities and groundwater pollution, identify high-risk areas where groundwater is easily polluted, and provide powerful tools for land use planning and groundwater resources management.

\section{Analysis of Related Concepts}

\subsection{Overview of Groundwater Pollution Risk Assessment in Northeast China}

In the 1980s and 1990s, in response to groundwater pollution caused by non-point source pollution, researchers recognized the inherent vulnerability of groundwater and the complex relationship between pollution and pollution risks: even when there is no obvious pollution risk, It is also a high-vulnerability area [2]. In the 1980s, Varnes proposed the "risk"="vulnerability" × "disaster" model, and introduced the "disaster theory" into the groundwater pollution risk assessment system. In practice, this risk characterization 
method is sometimes simply treated as B. "risk"="intrinsic vulnerability" $\times$ "probability of pollutants exceeding the standard $n, n$, which is really applicable to groundwater pollution risk research by disaster risk theory small [3].

The research on groundwater pollution risk assessment has just started and lacks systems and methods. Based on the evaluation of groundwater sensitivity, Zhang Xuegang et al. Point sources as groundwater pollution risk assessment indicators Zhang Weihong suggested that three aspects must be fully considered when assessing groundwater pollution risks: the inherent vulnerability of aquifers, the risk of exposure to pollution sources, and pollution hazards [4]. These index systems are very useful for the further development and improvement of the groundwater pollution risk assessment index system.

\subsection{The Concept of Indicative Factors of Groundwater Pollution in Northeast China}

The use of the term indicative in groundwater science can be traced back to the 1980s. Indicative research on groundwater has two aspects: On the one hand, other factors indicate the existence or nature of groundwater, such as plant research shows the existence of groundwater. A preliminary study on the indicators of soil and groundwater plant communities in Xinjiang. On the other hand, certain elements (components, microorganisms, compounds, organic matter) in groundwater indicate changes in the groundwater environment, groundwater pollution, or pollution sources. The importance of hydrogeochemical information to the characteristics of karst groundwater flow system, an indication of micro-components of water chemistry in Makeng mining area in Fujian; isotope indication, when the isotope and elemental composition of groundwater are recharged The impact of climatic conditions on the isotopic stratification of the Quaternary groundwater in northern China and its indicative significance. The higher the isotope value, the higher the annual average temperature, and the lower the isotope value, the lower the annual average temperature; microorganisms indicate groundwater pollution [5].

\section{Establishment of a Risk Assessment Index System for Groundwater Pollution in Northeast China}

\subsection{Principles for the Establishment of the Indicator System}

\subsubsection{The Principle of Spatial Scale}

According to the analysis of hydrogeological conditions and groundwater pollution characteristics in Northeast China, groundwater pollution characteristics have obvious characteristics of economies of scale [6]. Therefore, when designing and screening the index system of groundwater pollution indicators, the economy of scale should be considered first, and the groundwater pollution indicators should be developed by regional websites and websites.

\subsubsection{The Principle of Independence}

The structure of the indicator system must be scientific: the selection of indicators should objectively and truly reflect the status of groundwater pollution and its impact on the environment, reflect the law of groundwater utilization and the nature of pollution, and the development of groundwater pollution. The indicator system structure is reasonable, clear, simple and easy to understand, in line with reality. The meaning of the indicator is clear, and the indicator is relatively independent and stable.

\subsubsection{Functional Principle}

The indicator system should fully consider the quantification of indicators and the difficulty and reliability of data collection, make extensive use of existing statistical data, and select representative comprehensive indicators and main indicators. The indicators after processing must be simple, clear, clear, easy to understand, and highly comparable and measurable. It can be quantified and has strong operability.

\subsection{Indication of Indicators}

Based on the analysis of hydrogeological conditions, hydrogeochemical conditions, groundwater pollution, groundwater pollution source distribution, groundwater environmental monitoring and other factors in Northeast China, the target layer and standard layer were constructed with reference to the "Pressure Problem and Response" (PSR) model. The indicator layer is the indicator system of the groundwater pollution indicators in the framework. Pressure indicators show the causes of changes in groundwater pollution, such as human over-utilization of groundwater resources, accidental discharge of pollutants and other human behavior [7]; Response indicator layer shows various indicative indicators of groundwater pollution, including: elements, ions, compounds, isotopes, Scale factor, trend indicator factor.

\subsection{Method Construction}

\subsubsection{Analysis of Influencing Factors of Groundwater Pollution Risk in Northeast China}

Generally speaking, when assessing regional groundwater risks, process analysis is usually used to determine influencing factors. The sensitivity of groundwater and the source of pollution are regarded as the main determinants of pollution risk. In the environmental risk assessment, the assessment scope is divided into the degree and regional groundwater pollution, regional pollutant source assessment and regional pollutant health risk assessment.

\subsubsection{Improved Merleau Composite Index Method}

MÉREAU's comprehensive index method is mainly used to dynamically identify the correlation degree between water quality pollution indexes, and to screen out other non-main factors by identifying the main factors, and establish the correlation equation between different water quality pollution index and pollution degree: 


$$
\begin{gathered}
X_{1}=a_{11} f_{1}+a_{12} f_{2}+\ldots+a_{1 k} f_{k}+\varepsilon_{1} \\
X_{2}=a_{21} f_{1}+a_{22} f_{2}+\ldots+a_{2 k} f_{k}+\varepsilon_{2} \\
\ldots \\
X_{p}=a_{p 1} f_{1}+a_{p 2} f_{2}+\ldots+a_{p k} f_{k}+\varepsilon_{p}
\end{gathered}
$$

Correlation Equation

In the equation, the regression coefficient between different factors is aij — I coefficient of variable. In the concrete calculation, it is necessary to standardize every factor: $\mathrm{Z} \mathrm{i}=\mathrm{x}$ i -x $\mathrm{m} \sigma$ (2) formula, the standard treatment value of water pollution index, $\mathrm{mg} / \mathrm{l}$, the concentration of water pollution index, $\mathrm{mg} / \mathrm{l}$ [8]; The mean value of different standard values, $\mathrm{mg} / \mathrm{l}$; the standard value of variance between different indexes. The correlation degree of each water pollution index was tested after standardized treatment: $\mathrm{KMO}=\sum \sum \mathrm{i} \neq \mathrm{j}$ r ij $2 \sum \sum$ $\mathrm{i} \neq \mathrm{j}$ r ij $2+\sum \sum \mathrm{i} \neq \mathrm{j}$ p ij 2 Partial correlation coefficients of different water pollution indexes in Pij.

On the basis of correlation degree test, the variance contribution rate of each variable was calculated.

$$
\begin{gathered}
\mathrm{f}_{1}=\mathrm{b}_{11} \mathrm{f}_{1}+\mathrm{b}_{12} \mathrm{f}_{2}+\ldots+\mathrm{b}_{1 \mathrm{p}} \mathrm{f}_{\mathrm{p}} \\
\mathrm{f}_{2}=\mathrm{b}_{21} \mathrm{f}_{1}+\mathrm{b}_{22} \mathrm{f}_{2}+\ldots+\mathrm{b}_{2 \mathrm{p}} \mathrm{f}_{\mathrm{p}} \\
\ldots \\
\mathrm{f}_{\mathrm{k}}=\mathrm{b}_{\mathrm{k} 1} \mathrm{f}_{1}+\mathrm{b}_{\mathrm{k} 2} \mathrm{f}_{2}+\ldots+\mathrm{b}_{\mathrm{kp}} \mathrm{f}_{\mathrm{p}}
\end{gathered}
$$

The Variance Contribution Rate (2)

In the equation, the linear correlation between different water pollution factors and the variance contribution of different water pollution factors are obtained. On the basis of calculating the variance contribution rate of each pollution factor, the total cumulative variance contribution rate is calculated: $\mathrm{F}=\sum \mathrm{i}=1 \mathrm{~m} \mathrm{~F}$ i W i (5), the total variance contribution rate of $\mathrm{F}--\mathrm{F}$ is $\%$, and the variance contribution rate of single water pollution factor is $\%$ The index number of $\mathrm{M} \sim \mathrm{X}, \mathrm{WI} \sim \mathrm{X}$ with different index weight, the index weight of traditional Merleau synthetic index is subjective, so this paper improves it, the weight calculation equation is introduced to calculate the weight of each Pollution Index: In the formula of $w i=\lambda i / \sum i=1 \mathrm{~m} \lambda \mathrm{i}$ (6) [9].

\section{Evaluation Steps}

\subsection{Groundwater Vulnerability Assessment in Northeast China}

Groundwater vulnerability refers to the degree to which groundwater in its natural state is susceptible to external pollution. The DRASTIC INDEX method is used to evaluate where D: buried depth of groundwater, R: net new stratum, A: aquifer medium, S: soil medium; T: topography; I: influence of unsaturated zone; $\mathrm{C}$ : calculation formula of aquifer permeability coefficient:

DRASTICIndex $=\mathrm{DrDw}+\mathrm{DrDw}+\mathrm{ArAw}+\mathrm{SrSw}+\mathrm{TrTw}+\mathrm{IrIw}+\mathrm{C}$ $\mathrm{rCw}$

\section{The DRASTIC INDEX}

In the formula, $\mathrm{Dr}, \mathrm{Rr}, \mathrm{Ar}, \mathrm{Sr}, \mathrm{Tr}, \mathrm{Ir}, \mathrm{Cr}$ are the graded values of each factor respectively; $\mathrm{Dw}, \mathrm{Rw}, \mathrm{Aw}, \mathrm{Sw}, \mathrm{Tw}, \mathrm{Iw}, \mathrm{Cw}$ are the weighted values of each factor respectively.

The vulnerability of aquifers is a relatively vague concept, so the continuous change of the index is considered when calculating the relative membership of the sample index $r_{i j}[10]$, Replace the index quota in the DRASTIC model. Divide each parameter value into 10 levels of index standard eigenvalues for identification, then there is a 7x10 level index standard eigenvalue matrix:

$$
Y=r_{i h}
$$

7x10 Level Index Standard Eigenvalue Matrix

Where:

$y_{i h}$ Is the standard characteristic value of index i for level h,

$$
i=1,2, \cdots, 7 ; h=1,2, \cdots, 10
$$

Assuming that there are $\mathrm{n}$ samples to be evaluated, and each sample has $\mathrm{m}$ evaluation indicators, construct the evaluation index eigenvalue matrix based on the measured data:

$$
X=x_{i j}
$$

Igenvalue Matrix

The relative membership degree of extremely difficult pollution is measured by each index:

$$
r_{i j}=\left\{\begin{array}{c}
0, x_{i j} \geq y_{i 10} \text { OR } x_{i j}<y_{i 10} \\
\frac{x_{i j}-y_{i 10}}{x_{i 1}-y_{i 10}}, y_{i 1}>x_{i j}<y_{i 10} \text { OR } y_{i 1}<x_{i j}<y_{i 10} \\
1, x_{i j} \leq y_{i 1} \\
x_{i j}>y_{i 1}
\end{array}\right.
$$

The Relative Membership Degree (6)

Convert matrix $\mathrm{X}$ into index relative membership degree matrix $R$ :

$$
R=r_{i j}
$$

According to the relative degree of membership, calculate the ratio of the characteristic value of the evaluation index of the sample to be evaluated under the Ith evaluation index:

$$
p_{i j}=r_{i j} / \sum_{j=1}^{n} r_{i j}
$$

And the Ith evaluation index is:

Ratio of The Characteristic Value Of The Evaluation Index The weight of the corresponding Ith evaluation index is:

$$
w_{i}=\left(1-e_{i}\right) / \sum_{j=1}^{m}\left(1-e_{i}\right)
$$

Ith Evaluation 
Furthermore, a fuzzy comprehensive evaluation model of groundwater vulnerability based on DRASTIC can be constructed, namely $\mathrm{H}$. Vulnerability relative membership vector:

$$
u_{i}=\sum_{j=1}^{n} w_{i} r_{i j}
$$

\section{Comprehensive Evaluation}

Where, $u_{i}$ Groundwater vulnerability index; $r_{i j}$ Groundwater vulnerability index; $w_{i}$ Weight.

The index factors in the DRASTIC evaluation method are fixed, but the relative importance of factors affecting groundwater vulnerability varies in different regions [11], and the evaluation index system should be different. The regional evaluation index system is combined with fuzzy discussion theory, and the index weight is determined according to the above formula. By creating a groundwater vulnerability classification map, the special vulnerability of regional groundwater is evaluated and characterized [12].

\subsection{Evaluation of Characteristics of Pollution Sources in Northeast China}

Fully consider the pollution level, migration, toxicity and degradability of characteristic pollutants, combined with the blacklist of priority control pollutants in my country's waters and the list of aquatic environmental pollutants priority control by the U.S. Environmental Protection Agency, the $\mathrm{m}$-type target load is screened to reflect regional pollutant sources Characteristic pollutants, establish a comprehensive evaluation method for multi-index pollutants. Use formula to rate it and get pollutant rating index $S_{i}$; Then use the formula to calculate. The comprehensive evaluation index $\mathrm{S}$ for each pollution source, and the establishment of a comprehensive evaluation layer for pollution sources:

$$
S_{i}=\sum_{j=1}^{m} k_{r j} k_{w j}
$$

Comprehensive Evaluation In the formula, $\mathrm{m}$ is the number of target pollutant parameters; $\mathrm{k}$ : is the target pollutant. The parameter classification value $\mathrm{k}$ is the weight of the target pollutant parameter. Use fuzzy analytic hierarchy process to determine the pollutant parameter weight k. First select $n$ pollution sources in the study area and the nature of the pollution sources (such as pollution degree, mobility, toxicity, etc.), determine the priority relationship matrix $F=9$, determine the fuzzy consistency matrix according to formula (10) $\mathrm{Q}=9$ and then according to Formula calculate weight:

$$
\begin{gathered}
q_{i j}=\frac{q_{i}-q_{j}}{2 x}+0.5 \\
q_{i}=\sum_{j=1}^{x} f_{i j}
\end{gathered}
$$

$$
\begin{gathered}
k_{w j}=\frac{s_{i}}{\sum_{i=1}^{s} s_{i}} \\
s_{i}=\left(\prod_{j=1}^{x} q_{i j}\right)^{\frac{1}{x}}
\end{gathered}
$$

Fuzzy Consistency Matrix

\subsection{Health Risk Assessment of Characteristic Pollutants in Northeast China}

Use the health risk assessment model recommended by the US EPA combined with toxicology knowledge to identify the hazards of regional characteristic pollutants, and determine whether the regional characteristic pollutants have carcinogenic or non-carcinogenic risks; the exposure of harmful factors and the health of the exposed population are measured through dose changes Evaluation. Quantitatively assess the relationship between the occurrence of effects, and conduct the exposure assessment of the population in the area to the characteristic pollutants under different exposure pathways, and the assessment table is given with quantitative weights. The lifetime average daily exposure is usually used as a dose for assessing health risks, and a formula is used to calculate the exposure:

Average birthday dose $=$ Total dose $/$ weight* $/$ lifetime time

Total dose $=$ Concentration of pollutants* Exposure frequency* Exposure duration* Absorption factor

Carry out risk characterization on the basis of exposure assessment, estimate the possible health hazard intensity and the probability of certain health effects under different conditions, and the formula for the health risk assessment model of non-carcinogenic pollutants:

$$
P=\frac{D}{R f D} * 10^{-6}
$$

The Health Risk Assessment Model

In the formula, $\mathrm{D}$ is the average daily exposure dose per unit weight of non-carcinogenic pollutants; $\mathrm{P}$ is the lifetime risk of specific health hazards. The health risk assessment model of carcinogenic pollutants is as follows:

$$
p=1-\exp (-q D)
$$

The Health Risk Assessment Model

In the formula, $\mathrm{P}$ is the increase in carcinogenic risk, $\mathrm{D}$ is the average daily exposure dose of chemical carcinogens per unit body weight, $\mathrm{T}$ is the carcinogenic intensity coefficient. Creation, pollutant source analysis, health risk. Develop corresponding methods for regional characteristic pollutant risk assessment, and create groundwater sensitivity classification and comprehensive pollution source map. 


\section{Example Application}

\subsection{Regional Groundwater Quality Status}

Taking Jinzhou area in west Liaoning as an example, the shallow groundwater depth in Jinzhou area is generally between $25 \mathrm{~m}$ and $75 \mathrm{~m}$, and the annual average value of total groundwater exploitation is $4.2105 \mathrm{~m}^{3} / \mathrm{d}$. With the rapid development of regional economy and society, the demand of water for agriculture, Industry and daily life is increasing year by year, and the demand of groundwater is also increasing. Based on data analysis of groundwater quality monitoring sites in Jinzhou area, the regional groundwater hardness ranges from $105 \mathrm{mg} / \mathrm{l}$ to $600 \mathrm{mg} / \mathrm{l}$, and the average hardness is $335 \mathrm{mg} / \mathrm{l}$. The $\mathrm{PH}$ value of each monitoring point is between 5.4 and 7.3, and the total $\mathrm{pH}$ value is weak alkalinity. The concentration of solid solutes ranged from 160 to $1000 \mathrm{MG} / \mathrm{L}$, and the average concentration of solid solutes in groundwater was $330 \mathrm{mg} / \mathrm{l}$. Combined with the data of 18 water quality indexes such as ammonia and nitrogen in 18 groundwater monitoring sites in the region, the interval statistical analysis of each pollution index was carried out [13].

\subsection{Standardized Values for Indicators}

Considering that different water pollution indexes have different influence on groundwater environment, it is necessary to standardize the treatment of various pollution indexes. The standardized treatment of various water quality indicators is an important way to eliminate the influence among the indicators. The results from the standardized treatment of water quality indicators at various groundwater monitoring points can be seen, nitrates and heavy metals have higher standardized treatment values, which have a higher impact on regional groundwater quality. They are also the main indicators of water quality exceeding the standard in Jinzhou in recent years.

\subsection{Result of Identification of Contamination Factor}

Based on a standardized analysis of 18 major pollution indicators, the contribution of variance to the pollution factors of groundwater monitoring sites in the Jinzhou area was quantitatively calculated using the modified Mero composite index, the main pollution factors were identified by the variance contribution rate. The results of variance contribution rate calculation are shown in Table 3. Before the analysis of the variance contribution rate of each water quality monitoring index, the data of each index is tested, through the data test, there is a certain degree of correlation between each water quality index, so it can be used as the data sample of the variance contribution rate analysis. The results show that nitrate is the main pollution factor of shallow groundwater in the region, and its contribution rate is $49.30 \%$. Next is ammonia nitrogen, its variance contribution rate is $43.66 \%$. The variance contribution of each heavy metal index is less than $10 \%$, which is not the main factor, mainly because the heavy industry in Jinzhou is relatively few, mainly agriculture, so the heavy metal concentration in industrial wastewater is relatively low. As the characteristic value of the weight calculation of each water quality index, its size determines the weight of the index. The analysis mainly uses the logarithmic statistical method, taking each water quality index as the horizontal coordinate and its concentration value as the vertical index, taking the probability of $75 \%$ as the index probability interval, the peak value of the probability interval as the upper end and the trough as the lower end, when the average concentration of each index is close to the upper end, the concentration distribution is considered to satisfy the normal distribution change, and the concentration is the characteristic value of the index, the larger the index EIGENVALUE is, the higher its influence weight is, and the larger its variance contribution rate is. This method can improve the subjectivity of weight setting of Traditional Mero index and improve the objectivity of factor identification.

\subsection{Spatial Analysis of Pollution Source Types}

In order to analyze the source and type of groundwater pollution in Jinzhou area, the orthogonal rotation method was used to calculate the rotating load of each index, in addition, 5 common factors with high degree of correlation were selected to carry out spatial interpolation analysis. The results are shown in Figure.

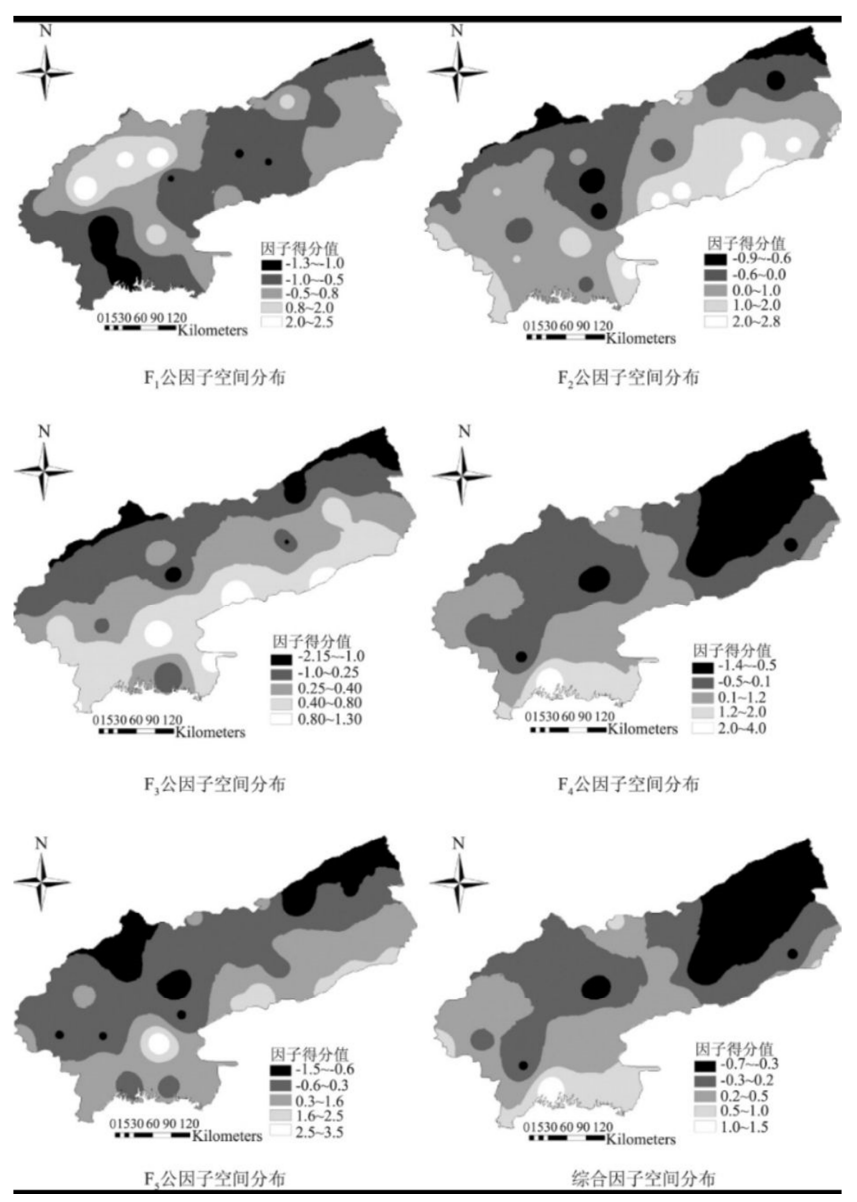

Figure 1. Comprehensive Common Factor Distribution Chart. 
Table 1. Spatial Interpolation Analysis.

\begin{tabular}{ll}
\hline Common Factor & Contribution ratio \\
\hline F1 & 48.5 \\
F2 & 12.35 \\
F3 & 10.25 \\
F4 & 9.42 \\
F5 & 8.49 \\
\hline
\end{tabular}

The load factor higher than 0.5 was chosen as the common factor of the main correlation index. The analysis results showed that the contribution ratio of common factor F1 was $48.5 \%$, and the main correlation indexes were nitrate and ammonia nitrogen, respectively, the nitrate beds in the areas with high groundwater enrichment in the Jinzhou area have high permeability, the groundwater is effectively supplied by the precipitation, and the underground runoff can greatly promote the formation of nitrate and other compounds in the rocks, in addition, agricultural non-point source and domestic sewage discharge also make the concentration of these pollutants increased significantly. The contribution ratio of common factor $\mathrm{F} 2$ is $12.35 \%$, and the main index of this common factor is heavy metal, which belongs to the main source type of industrial waste water. The index of heavy metal in groundwater in Jinzhou area has certain homology, the results of common factor spatial interpolation show that the areas with factor scores higher than 1.0 are mainly located in the southwest of Jinzhou. Through field investigation, the areas are mainly mines and industrial parks in Jinzhou, the heavy metal concentration in industrial wastewater and mine drainage is relatively high due to the combined action of precipitation and groundwater transport. The contribution ratio of common factor $\mathrm{F} 3$ is $10.25 \%$, and its main correlative index is COD. The COD of shallow groundwater mainly comes from agricultural non-point source, aquaculture industry and domestic sewage discharge, the area with a factor score of 0.4 was mainly in the central part of the Jinzhou region, which was concentrated in residential areas and livestock breeding areas, domestic sewage and rural domestic refuse are affected to different degree by the groundwater pollution caused by the erosion of rainwater [14]. The contribution ratios of common factors F4 and F5 are 9.42\% and $8.49 \%$ respectively. The correlation indexes of these two common factors are similar to some extent, the main sources are ammonia nitrogen and nitrate, and the main sources are domestic sewage, it is mainly concentrated in residential areas. Based on the analysis of common factors, it can be seen that the pollution of shallow groundwater in Jinzhou area has the characteristics of multi-source, which is composed of domestic sewage, agricultural non-point source, mine drainage and industrial wastewater, among them, $46.5 \%$ of shallow groundwater pollution mainly comes from domestic sewage discharge, $37.5 \%$ from agricultural non-point source and livestock breeding, $16.0 \%$ from industrial wastewater and mine drainage. The higher the score of common factor distribution, the higher the pollution degree, and the higher the pollution degree, the lower the pollution degree in the north.

\section{Conclusion}

Groundwater pollution risk research based on groundwater vulnerability assessment started late and is still in the exploratory stage. It investigates and establishes a series of groundwater pollution risk assessment index systems, and proposes a method for groundwater pollution risk assessment based on disaster risk. The theoretical pollution risk improves the accuracy and scientificity of groundwater pollution risk assessment, making it a powerful decision support tool for land use planning and groundwater resources protection and management. When the modified Mero composite index is adopted, the characteristic values of each index can be obtained by drawing the probability distribution curve of the index concentration, and the upper limit of the probability of the index concentration is $75 \%$, and the corresponding concentration is the characteristic value of the index when the probability of the index concentration is close to the upper limit. To strengthen the control of domestic sewage and agricultural non-point source pollution in northeast China, designate it as a key treatment area and protection area, strengthen the extension of sewage treatment and ecological fertilizer, strengthen the recharge of groundwater, and restore the water level in the funnel area, reduce the effect of leakage [15].

\section{References}

[1] A GIS-based LVF model for semiquantitative assessment of groundwater pollution risk: A case study in Shenyang, NE China [J]. Human \& Ecological Risk Assessment An International Journal, 2016: 276-298.

[2] Alexander W. Research on the conjunctive regulation of surface water and groundwater in Shifosi water works [J]. Journal of Geoscientific Research in Northeast Asia, 1998, 42 (1): 54-55.

[3] Bai Fengqing, Liang Tieshan. [J] groundwater pollution and water source protection in Jinzhou. Journal of Hebei Institute of Building Science and Technology, 2003 (2): 9-12.

[4] Chen Z, Wen W, Liu J, et al. Identifying the recharge sources and age of groundwater in the Songnen Plain (Northeast China) using environmental isotopes [J]. Hydrogeology Journal, 2011, 19 (1): 163-176.

[5] Huan, Wang, Teng. Assessment and validation of groundwater vulnerability to nitrate based on a modified DRASTIC model: A case study in Jilin City of northeast China.

[6] Huan, Zhang, Bo-Tao, et al. Comprehensive assessment of groundwater pollution risk based on HVF model: A case study in Jilin City of northeast China [J]. Science of The Total Environment, 2018, 628-629 (1): 1518-1530.

[7] Jian-Fei L U, Gan H Y, Sui-Shan X U. Applications of RPs and RQA in the shallow groundwater along the northeast coast of Hainan in China [J]. Marine Science Bulletin, 2017.

[8] Lu Zhijia. Pollution remediation and risk management of decommissioned industrial sites [J]. Green Technology, 2020 (24): 108-110. 
[9] Liuli Liu, Yirong Deng, Rintei, et Al. Groundwater stratification investigation and risk assessment in typical chemical sites in Guangdong-hong Kong-macao Bay area [J]. Environmental Pollution and prevention, 2021, 43 (1): 67-72, 78.

[10] Neshat A, Pradhan B. Risk assessment of groundwater pollution with a new methodological framework: application of Dempster-Shafer theory and GIS [J]. Natural Hazards, 2015, 78 (3): 1565-1585.

[11] Sun Hong, Wang Wenzhi, Zhang Guofei, etc. Study on groundwater pollution prediction and preventive measures by tailwater discharge from a sewage plant in Shanghai $[\mathrm{J}]$. Water Planning and design, 2020 (11): 86-88, 140.
[12] Tian Zhenjun. Trend analysis of shallow groundwater quality in Cangzhou [J]. Journal of Hebei Institute of Water Conservancy and electric power, 2020, 30 (4): 54-57.

[13] Wang X, Liu Z, Wang C, et al. Occurrence and formation potential of nitrosamines in river water and ground water along the Songhua River, China [J]. Journal of Environmental Sciences, 2016.

[14] Wang Zhining and Li Jing. Impact analysis of groundwater exploitation in environmental geology [J]. Low Carbon world, 2021, 11 (1): 146-147.

[15] Yang JF, Wan S Q, Chen X H. An Evaluation of Groundwater's Role in Regional Economic and Social Development in China [J]. resources science, 2007, 29 (5): 97-104. 